\title{
A sliding-neural network control of induction-motor-pump supplied by photovoltaic generator
}

\author{
Hichem Hamdi, Chiheb Ben Regaya and Abderrahmen Zaafouri
}

\begin{abstract}
Energy production from renewable sources offers an efficient alternative non-polluting and sustainable solution. Among renewable energies, solar energy represents the most important source, the most efficient and the least expensive compared to other renewable sources. Electric power generation systems from the sun's energy typically characterized by their low efficiency. However, it is known that photovoltaic pumping systems are the most economical solution especially in rural areas. This work deals with the modeling and the vector control of a solar photovoltaic (PV) pumping system. The main objective of this study is to improve optimization techniques that maximize the overall efficiency of the pumping system. In order to optimize their energy efficiency whatever, the weather conditions, we inserted between the inverter and the photovoltaic generator (GPV) a maximum power point adapter known as Maximum Power Point Tracking (MPPT). Among the various MPPT techniques presented in the literature, we adopted the adaptive neuro-fuzzy controller (ANFIS). In addition, the performance of the sliding vector control associated with the neural network was developed and evaluated. Finally, simulation work under Matlab / Simulink was achieved to examine the performance of a photovoltaic conversion chain intended for pumping and to verify the effectiveness of the speed control under various instructions applied to the system. According to the study, we have done on the improvement of sliding mode control with neural network. Note that the sliding-neuron control provides better results compared to other techniques in terms of improved chattering phenomenon and less deviation from its reference.
\end{abstract}

Keywords: Maximum power point tracking (MPPT), Adaptive Neuro-fuzzy inference systems (ANFIS, Photovoltaic (PV) systems, Fuzzy logic controller (FLC), Pump, Sliding mode controller

\section{Introduction}

Human beings need abundant amount of energy at an increasing rate for their sustenance and good living. Nowadays, this energy is mostly derived from fossil fuel such as coal, oil, natural gas and from nuclear power. But the above resources are not at all stable and reliable. The non-renewable resources like fossil fuel will last only about $50-75$ years. In this era, other alternatives like renewable resources such as solar, tidal, wind etc. have to be considered [1].

Of these resources, solar systems are gaining an increasing interest and they are becoming a very

\footnotetext{
*Correspondence: hichem.hamdi@isetsbz.rnu.tn

University of Tunis, Higher National Engineering School Of Tunis (ENSIT), Engineering Laboratory of Industrial Systems and Renewable Energies (LISIER), 5 avenue Taha Hussein, PO Box 56, 1008 Tunis, Tunisia
}

competitive solution, because many sunny days are available throughout the year. Moreover, environmental issues such as population and global warming effects are driving incites researchers towards the development of renewable energy sources including solar systems. The production of electricity in solar systems is based on solar cells where the photons are absorbed by a semiconductor converted directly into electrical energy. The electrical power / voltage characteristic of a photovoltaic generator (GPV) represents the variation of the power as a function of the voltage across the GPV. In this feature, the GPV contains an optimal operating point generally referred to as the maximum power point and is in a non-linear area. To improve the efficiency of the photovoltaic (PV) system, it is necessary to set up an optimal power point follower. 


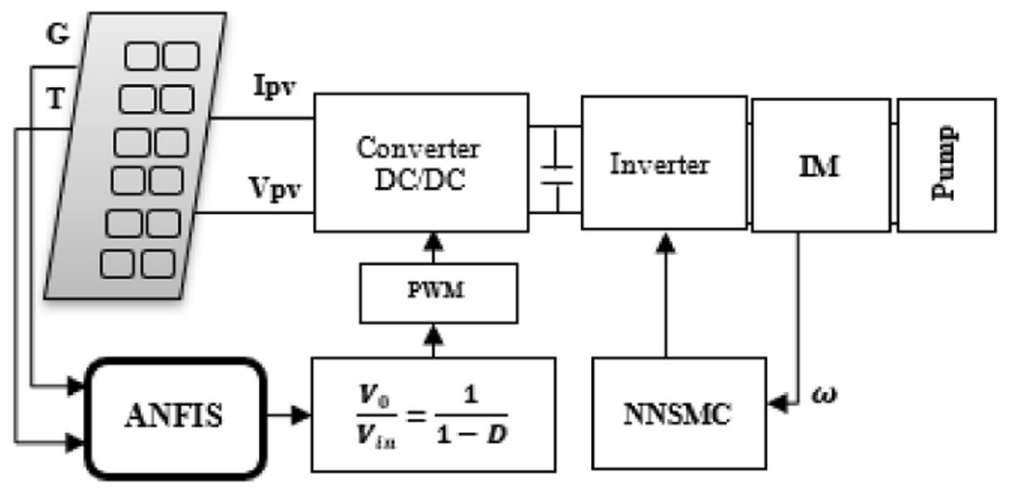

Fig. 1 Synoptic diagram of a pumping system

There are several methods for obtaining the maximum power of the photovoltaic generator [2], the most common methods are: Perturbation and Observation ( $\mathrm{P} \& \mathrm{O})$ [3], the incremental conductance [4], most of these algorithms fail to track the maximum power point regularly. For this reason, methods based on "artificial intelligence" are used. Among these methods, the authors $[5,6]$ proposed the MPPT algorithm based on artificial neural networks. The authors in $[7,8]$, proposed genetic algorithms and in $[9,10]$, they used fuzzy logic to obtain the optimal power point. In this paper, an adaptive network based fuzzy inference system (ANFIS) control is used.

One of the most important applications of Photovoltaic (PV) systems is for water pumping, hence, in rural areas that have a considerable amount of solar radiation and have no access to national grids. An effective solution must ensure that the PV generator (GPV) runs at the maximum power point (MPP) and that the motor runs at a high efficiency level. In this category, several authors are interested in improving the performance of photovoltaic pumping systems. A number of DC motor driven pumps are already in use in several parts of the world [11], but they suffer from maintenance problems due to the presence of the commutator and brushes.

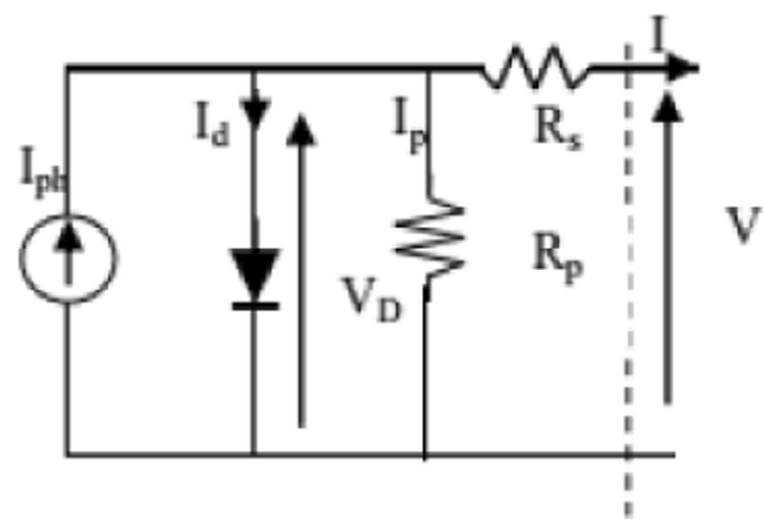

Fig. 2 General PV Cell Model
Hence, a pumping system based on an Induction Motor (IM) can be an attractive proposal where reliability and maintenance free operations are important [12, 13]. Several techniques for controlling a photovoltaic pumping chain have been used. They are built around different commands most used for electrical rotating machines. These orders are intended to analyze their performance in a photovoltaic pumping chain.

In particular, it contains the principles and configurations of direct and indirect vector control applied to the Synchronous Motor and Induction Motor [14]. Subsequently, the author [15] described direct torque control with conventional regulators such as Proportional Integral and intelligent controllers based on fuzzy logic. It seems that the PI regulators being limited by their dynamics and their sensitivities vis-à-vis the parametric variations. To overcome this drawback, the sliding mode control was considered. However, this control technique exhibits high frequency oscillations due to discontinuous control [16]. Therefore, in order to improve the performance, a control without speed sensors, associated with the sliding mode controller technique associated with neural network was analyzed.

This paper is organized as follows: In Section 2, the modeling of PV cell, DC-DC boost converter and the motor-pump are introduced. In Section 3, the adaptive neuro-fuzzy controller (ANFIS), and the sliding vector control associated

Table 1 Parameter values of YHM180-36 M PV panel

\begin{tabular}{ll}
\hline Optimum operation voltage & $35.20 \mathrm{~V}$ \\
\hline Optimum operation current & $05.11 \mathrm{~A}$ \\
Open-circuit voltage & $43.00 \mathrm{~V}$ \\
Short-circuit current & $05.5 \mathrm{~A}$ \\
Maximum power at STC & $180 \mathrm{~W}$ \\
Peak Efficiency & $16 \%$ \\
Temp. Coefficient of $I_{s c}$ & $-(0.06 \pm 0.01) \% / \mathrm{k}$ \\
Temp. Coefficient of $V_{o c}$ & $-(78 \pm 10) \mathrm{mV} / \mathrm{k}$ \\
Number of Cells & 72 \\
\hline
\end{tabular}



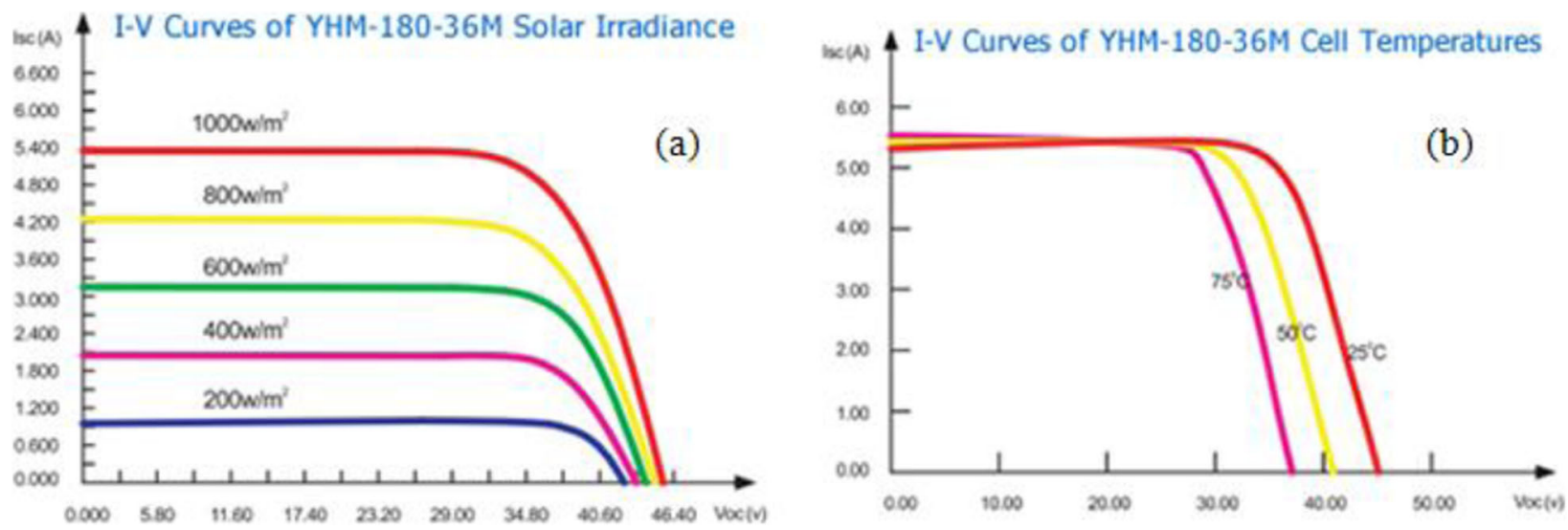

Fig. 3 Variations of MPP with changing: (a) Irradiation (b) Temperature

with the neural network was developed and evaluated. Simulation tests under Matlab / Simulink was achieved to examine the performance of a photovoltaic conversion chain intended for pumping and to verify the effectiveness of the speed control under various instructions applied to the system are given in Section 4. Finally, Section 5 summarizes the conclusions of the paper.

\section{System descriptions}

The proposed diagram of the photovoltaic pumping is shown in Fig. 1. The schematic consists of a PV array, a boost converter working as a maximum power point tracker (MPPT), an inverter and a motor driving a pump controlled by the neural networks with sliding mode controller.

\subsection{Photovoltaic Array}

A PV cell can be modeled from the equation defining the static behavior of the PN junction of a conventional diode. Thus, Fig. 2 illustrates the equivalent electrical diagram of a real PV cell.

In Fig. 2, we consider the short-circuit current and two resistors (series and shunt) modeling the losses due to the connections. In static, the behavior of a PV cell made up of a silicon-based PN junction can be described by the following equation:

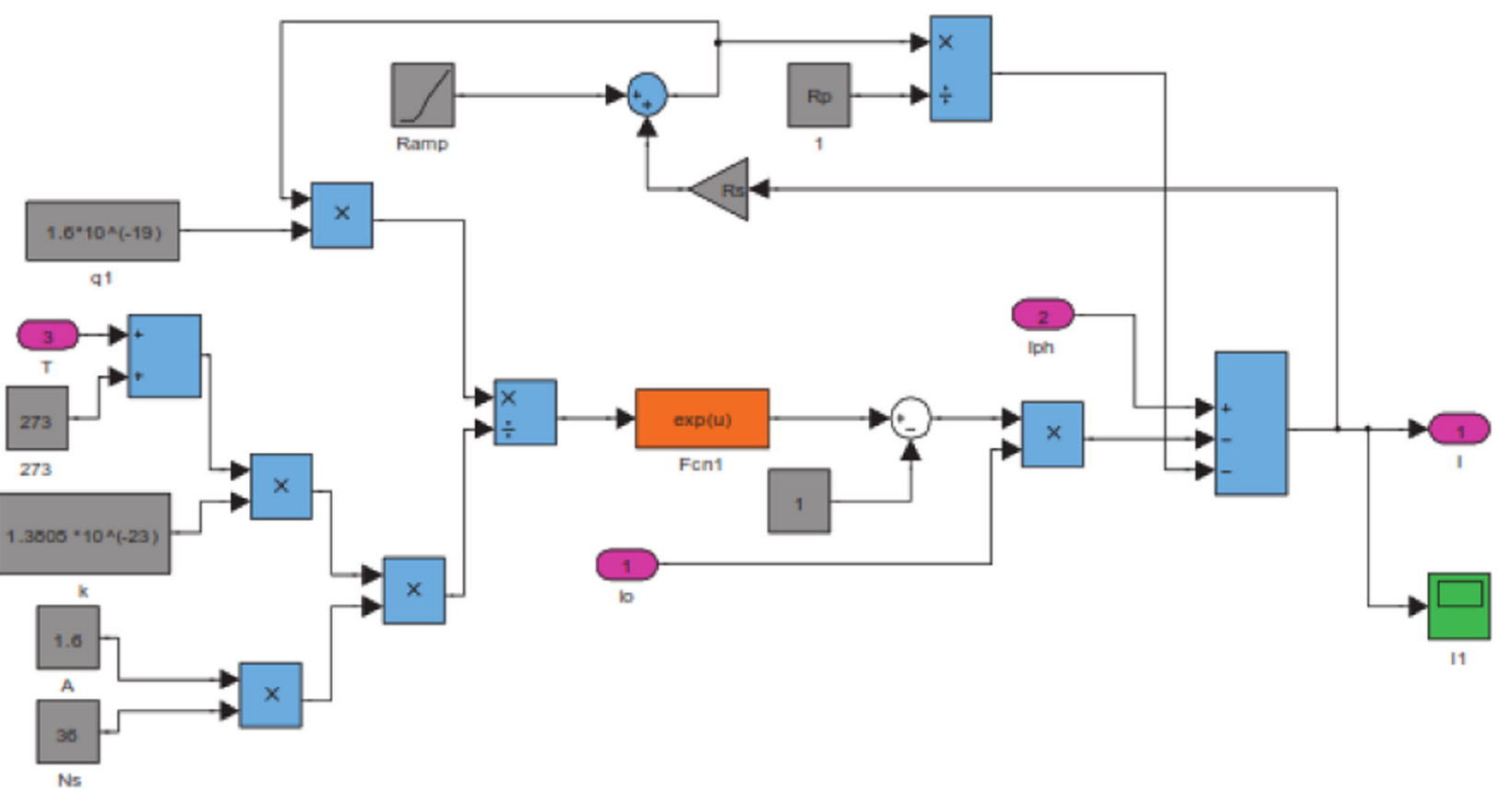

Fig. 4 PV model considering $R_{p}$ resistance 


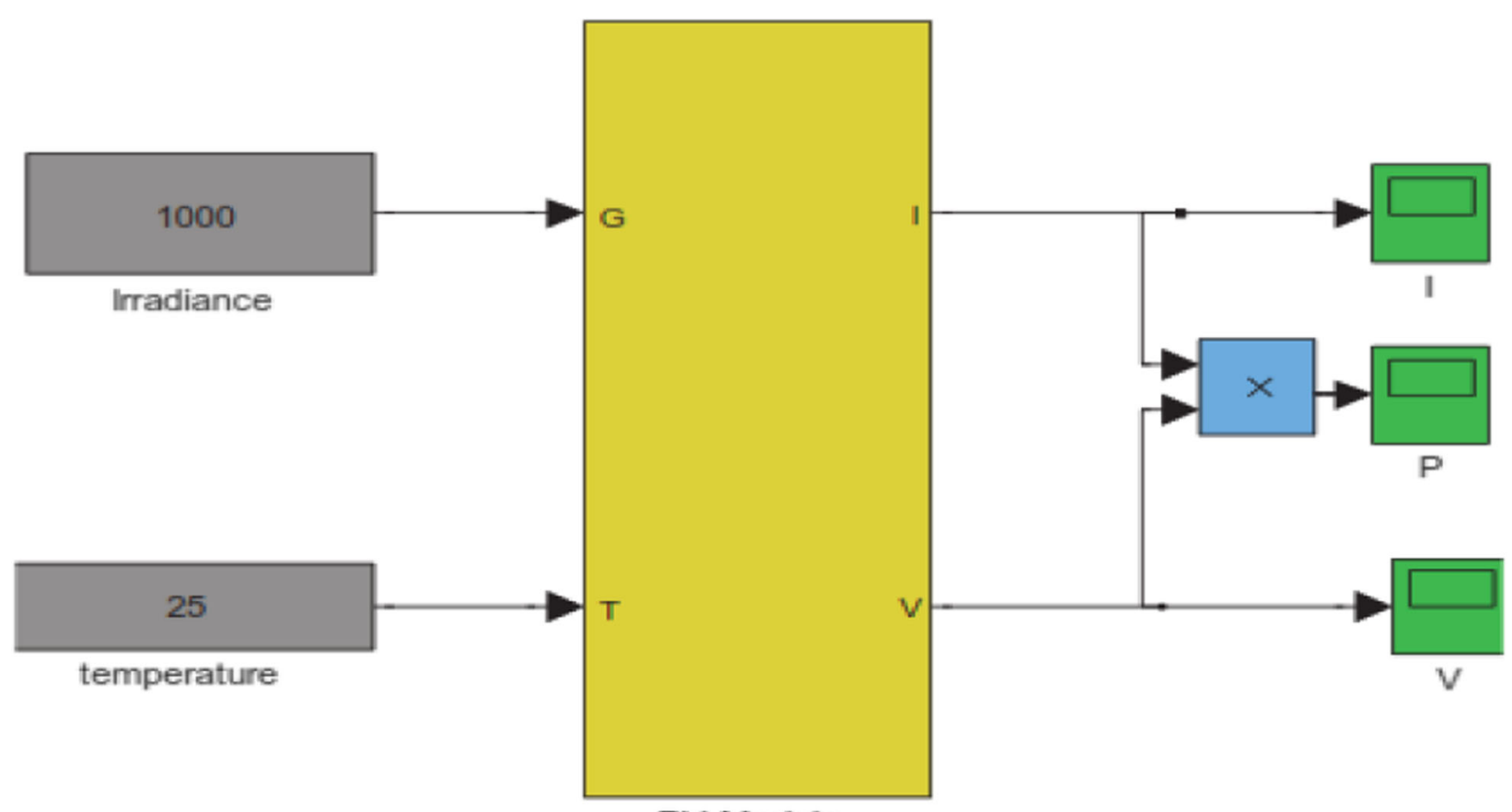

Fig. 5 Bloc scheme of PV model

PV Module

$$
I_{P V}=I_{p h}-I_{d}-I_{R_{p}}
$$

$$
I_{p h}=\frac{G}{G_{r e f}}\left(I_{s c, r e f}+\mu_{s c} . \Delta T\right)
$$

The value of $I_{p h}$ is heavily dependent on the irradiance $G$ and solar cell temperature $T_{c}$. The equation of $I_{p h}$ can be expressed as follows:
While the current flowing through the diode $I_{d}$ is given by eq. (3):

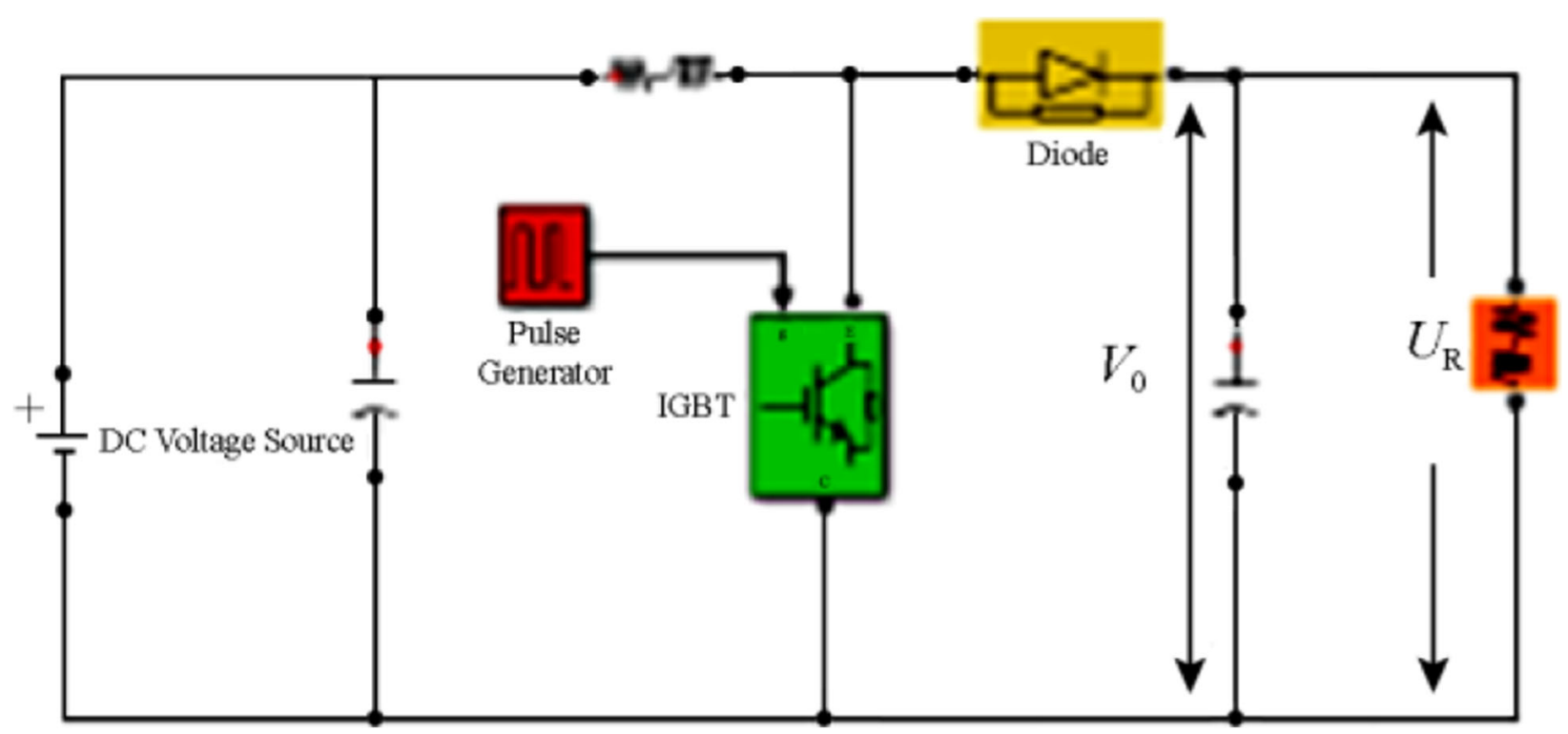

Fig. 6 Boost converter 
Table 2 Variation of $\mathrm{K}_{\mathrm{sp}}$ according to $\mathrm{N}_{\mathrm{sq}}$

\begin{tabular}{llll}
\hline$N_{s q}$ & 60 & 100 & 150 \\
\hline$K_{s p}$ & 0.00017 & 0.00030 & 0.00075 \\
\hline
\end{tabular}

$$
I_{d}=I_{0}\left[\exp \left(\frac{V_{P V}+I_{P V} \cdot R_{s}}{A \cdot V_{T}}\right)-1\right]
$$

Where $V_{T}=\frac{k \cdot T}{q}$.

Saturation current $I_{0}$ of solar cells can be expressed in a mathematical equation that has a relationship with the temperature of the solar cell as follows [8]:

$$
I_{0}=a_{0} \cdot b_{0}^{3} \cdot \exp \left(q \cdot E_{g}\left(\frac{1}{T_{c, r e f}}-\frac{1}{T_{c}}\right) \cdot(A \cdot k)^{-1}\right)
$$

Where $a_{0}=\frac{I_{s, \text { reef }}}{\exp \left(\frac{V_{\text {occef }}}{a}\right)-1}$ and $b_{0}=\frac{T_{c}}{T_{c, r e f}}$.

The thermal voltage $a$ is presented by the following equation:

$$
a=\frac{N_{s} \cdot A \cdot k \cdot T_{c}}{q}
$$

The current $I_{R_{p}}$ in a closed loop can be determined by using Kirchhoff's voltage law analysis, which is expressed by eq. (6):

$$
I_{R_{p}}=\frac{V_{P V}+R_{s} I_{P V}}{R_{p}}
$$

Therefore, the output current $\mathrm{I}_{\mathrm{PV}}$ was previously expressed by eq. (1), can be rewritten as follows:

$$
I_{P V}=I_{p h}-I_{0}\left[\exp \left(\frac{V_{P V}+I_{P V} \cdot R_{s}}{A \cdot V_{T}}\right)-1\right]-\frac{V_{P V}+R_{s} \cdot I_{P V}}{R_{p}}
$$

A PV array is a group of several PV modules which are electrically connected in series $\left(N_{s}\right)$ and parallel $\left(N_{p}\right)$ for generating more power. The equivalent circuit of a PV array is expressed as follows:

$$
I_{P V}=N_{p} \cdot\left[I_{p h}-I_{0}\left[\exp \left(\frac{\frac{V_{P V}}{N_{s}}+\frac{I_{P V} \cdot R_{s}}{N_{p}}}{A \cdot V_{T}}\right)-1\right]\right]-\frac{\frac{V_{P V} \cdot N_{s}}{N_{p}}+R_{s} \cdot I_{P V}}{R_{p}}
$$

where:

$I_{P V}:$ Output current of solar cells (Ampere);

$I_{p h}$ : Photocurrent (Ampere);

$V_{P V}$ : Output voltage of solar cells (Volt);

$\mu_{s c}$ : Temperature coefficient of the short circuit current provided by the manufacturer;

$E_{g}$ : Silicon bandgap energy $\left(E_{g}=1.12 \mathrm{eV}\right)$;

$T_{c}$ : Temperature of the solar cell (Kelvin);

$T_{c, \text { ref: }}$ Reference temperature of Solar Cells (Kelvin); $G, G_{\text {ref }}$ Irradiance and reference irradiance;

$k$ : Boltzmann's constant $\left(1.381 \times 10^{-23} J / K\right)$;

$q$ : Electron charge $\left(1.60222 \times 10^{-19} \mathrm{C}\right)$;

$A$ : Ideality factor of PV technology $(1 \leq A \leq 2)$;

$I_{s c}, V_{o c}, V_{m p p}, I_{m p p}$ : Short circuit current, open circuit voltage, maximum power point current and voltage which are shown in Table 1.

The typical current-voltage (I-V) curve characteristics of the PV module are shown in Fig. 3.

The photovoltaic system model developed under MATLAB / Simulink is given by Figs. 4 and 5:

\subsection{DC-DC boost converter}

The power supplied by the photovoltaic generator is fed to a boost converter, which is controlled using the MPPT controller based on adaptive network based fuzzy inference system (ANFIS). The boost converter is used to boost the DC voltage of the panel. Duty cycle for switching is determined by the MPPT controller, which determines the present climatic condition and produces an optimum value of duty cycle, as shown in Fig. 6.

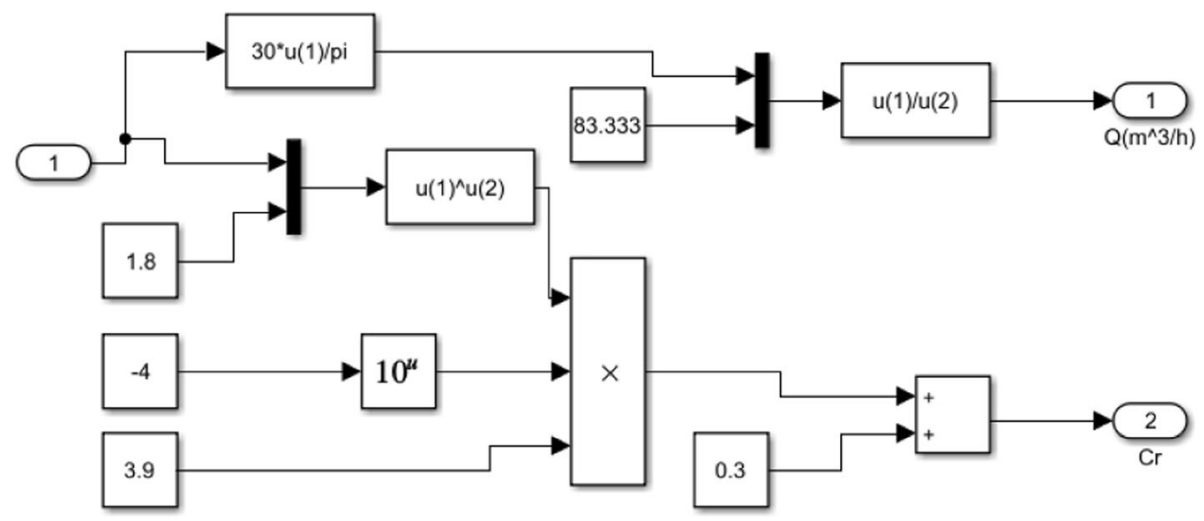

Fig. 7 Model of the centrifugal pump 


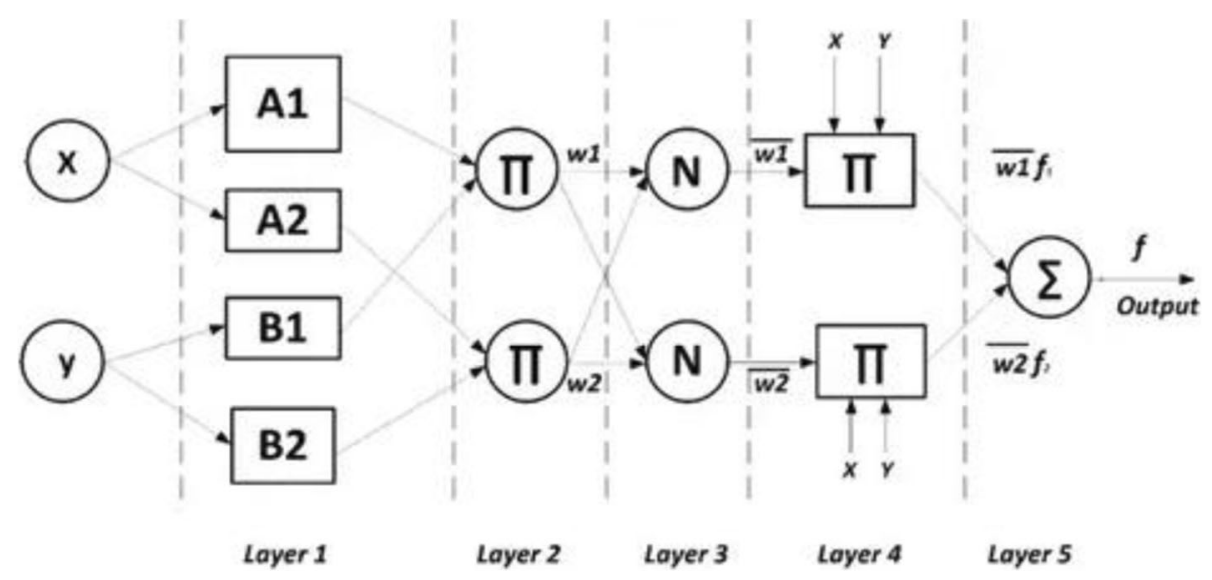

Fig. 8 Typical five-layer ANFIS system

In steady state, the output voltage of the boost converter can be calculated as [17]:

$$
V_{0}=U_{R}=\frac{1}{1-D} V_{\text {in }}
$$

where $D$ is the duty cycle of converter.

\subsection{Pumping subsystem Modelling}

A motor-pump consists of a centrifugal pump coupled with a three-phase induction machine. Several types of DC and AC motors are available for PV pumping systems. The choice of the motor is dependent on numerous factors including size requirement, efficiency, price, reliability and availability. Generally, the PV water pumping system needs a water tank for storing water. If there is no water tank or the system is used as potable equipment, the battery set will be necessary.

\subsubsection{Dynamic model of induction motor}

The electrical model of the induction machine in the $d$ q referential axis linked to rotating field is given by the following equation $[18,19]$ :

$$
\left\{\begin{array}{l}
V_{s d}=\left(R_{s}+\frac{R_{r} L_{m}^{2}}{L_{r}^{2}}\right) i_{s d}+L_{s} \sigma \frac{d i_{s d}}{d t}-\omega_{s} L_{s} \sigma i_{s q}-\frac{R_{r} L_{m}}{L_{r}^{2}} \phi_{r d} \\
V_{s q}=\left(R_{s}+\frac{R_{r} L_{m}^{2}}{L_{r}^{2}}\right) i_{s q}+L_{s} \sigma \frac{d i_{s q}}{d t}-\omega_{s} L_{s} \sigma i_{s d}-\frac{p \Omega L_{m}}{L_{r}^{2}} \phi_{r d}
\end{array}\right.
$$

The mechanical modeling part of the system is given by:

$$
J \frac{d \Omega}{d t}=C_{e}-C_{r}-f \Omega
$$

where, the electromagnetic torque is expressed by:

$$
C_{e}=p \frac{3 L_{m}}{2 L_{r}}\left(\phi_{r d} i_{s q}-\phi_{r q} i_{s d}\right)
$$

with:

$R_{s}, R_{r}:$ Stator and rotor resistances respectively;

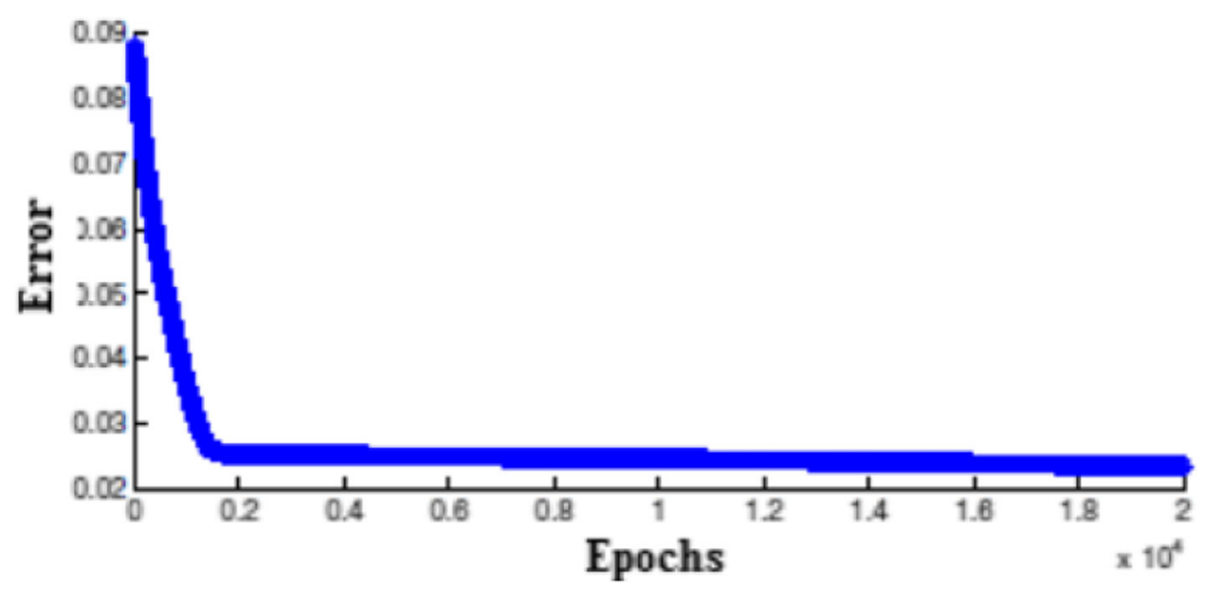

Fig. 9 Training error 


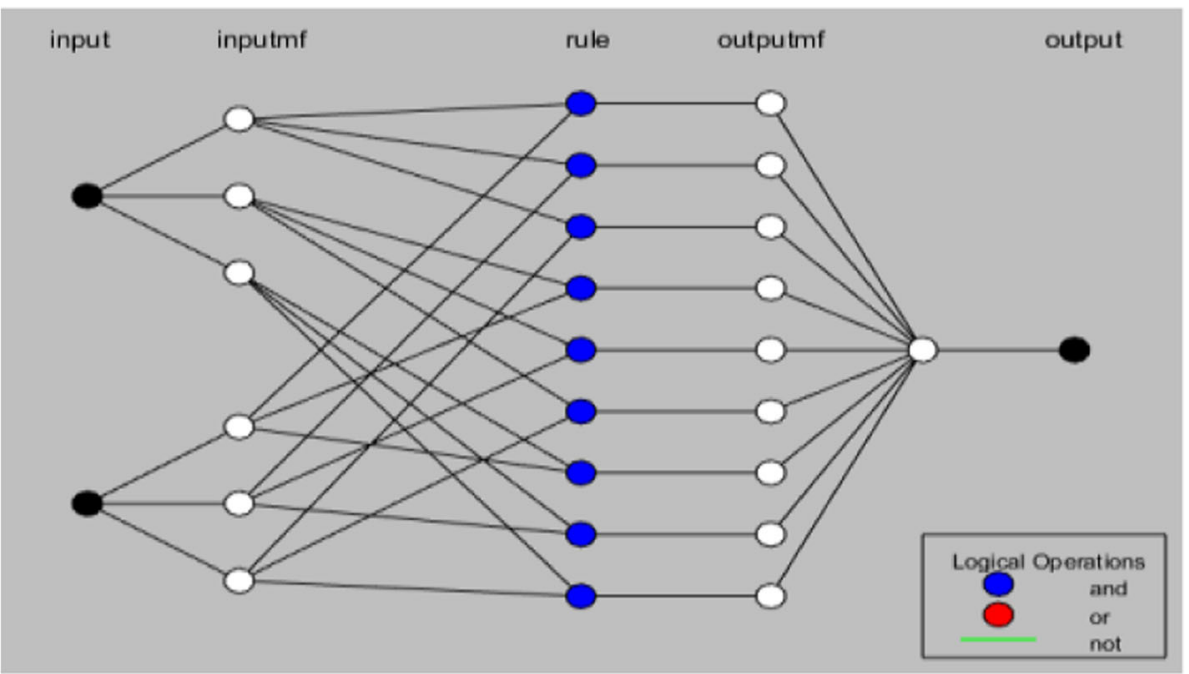

Fig. 10 ANFIS system

$L_{s}, L_{r}$ : Stator and rotor inductances respectively;

$L_{m}, \omega_{s}$ : Mutual inductance and Stator angular frequency;

$\Omega, \sigma$ : Rotor speed and total leakage coefficient;

$J, f$ : Total inertia and friction coefficient;

$C_{r}, p$ : Load torque and number of pole pairs.

\subsubsection{Pump model}

Many varieties of pumps are used with a PV pumping system. In our case, a centrifugal pump is considered. This type of pump is simple and requires a minimum of maintenance. In our case, we directly use the model expressing the output of the water flow $\left(Q_{n}\right)$ as a function of the speed of the rotor shaft in revolutions per minute at the engine pump, for different total loads.

A broad classification of pumps, directly related to the general shape of the rotor, is introduced from the definition of the specific diameter (eq. (13)) and the specific angular velocity (eq. (14)), two dimensionless numbers derived from the similarity of the turbomachines [20]:

$$
\begin{aligned}
& D_{s}=\frac{D\left(g H_{n}\right)^{\frac{1}{4}}}{\sqrt{Q_{n}}} \\
& N_{s}=\frac{\omega \sqrt{Q_{n}}}{\left(g H_{n}\right)^{\frac{3}{4}}}
\end{aligned}
$$

In general, pump manufacturers do not give the physical parameters of the pump. Only the performance characteristic $H=f(Q)$ is given by the manufacturer. Thus, knowing the values of speed, load height and reference flow, it is possible to determine those of the system using the following empirical formulas [21]:
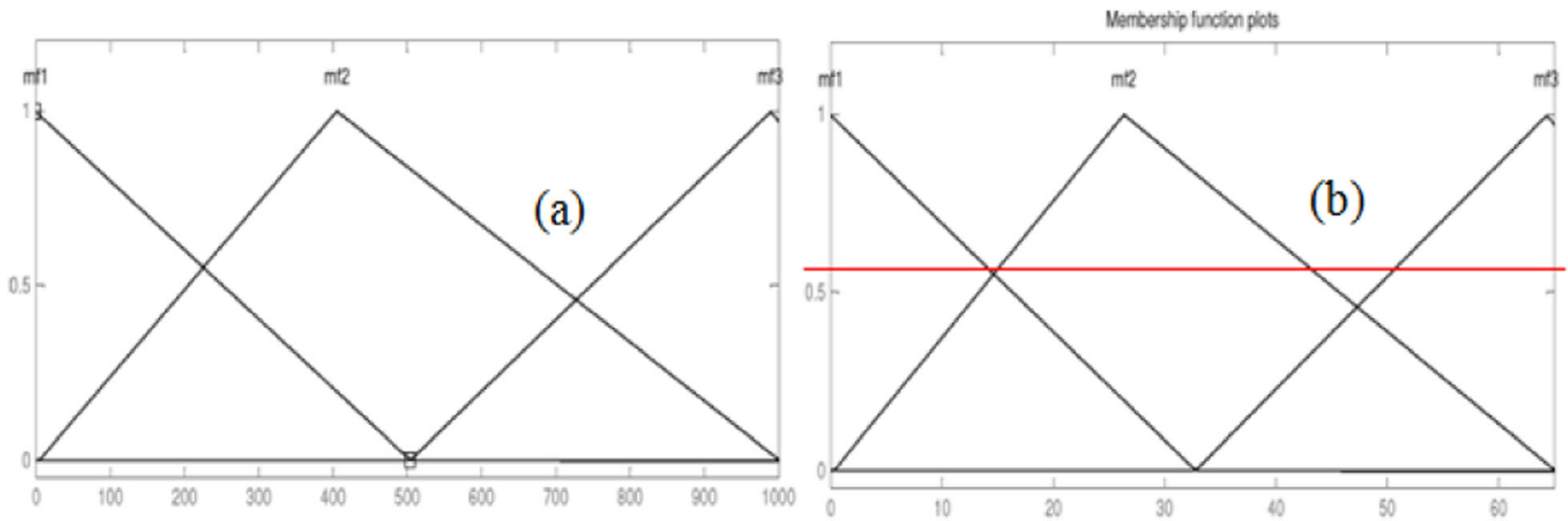

Fig. 11 Membership functions: (a) solar irradiance (b) PV cell temperature 


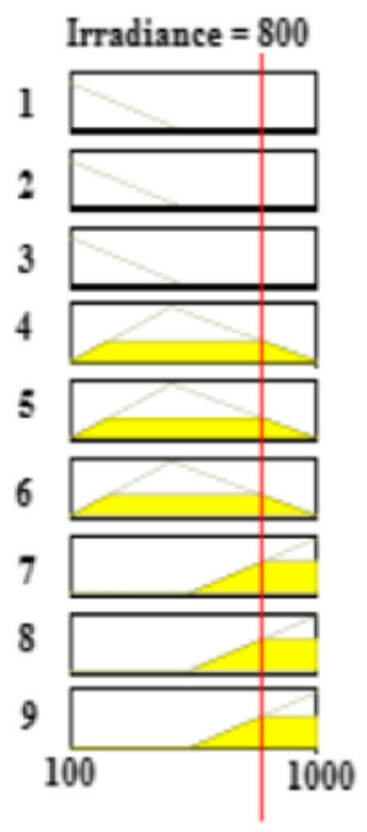

Fig. 12 Inputs and Outputs of ANFIS after Training

$$
\begin{aligned}
& N_{s q}=\frac{100\left(\frac{N}{60}\right) \sqrt{Q_{n}}}{\left(\frac{g H}{N_{e p}}\right)^{\frac{3}{4}}} \\
& Q_{n}=K_{s p} \cdot N \cdot\left(D_{f}\right)^{3} \\
& C_{r}=0.3+3.9 \times 10^{-4} \omega^{1.8}
\end{aligned}
$$

where $Q_{n}$ is the flow rate in $\mathrm{m}^{3} / \mathrm{h}, N$ is the speed of the rotor $(\mathrm{rpm}), K_{s p}$ is a constant that depends on the specific speed of the pump, $D_{f}$ is the diameter of the borehole, $C_{r}$ is the load torque, $N_{s q}$ : specific rotor speed, $g$ : Acceleration of gravity, $N_{e p}$ : pump number of stages and $\omega$ is the rotor speed in $\mathrm{rad} / \mathrm{s}$.
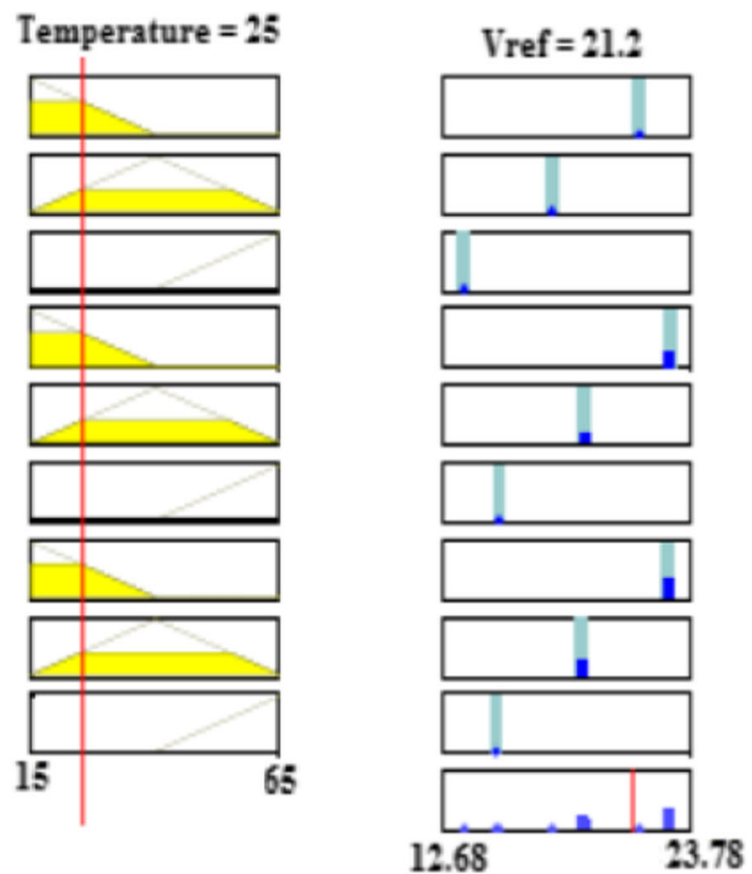

The variations of the specific speed pump according the specific rotor speed are given in Table 2:

The model of the proposed centrifugal pump is shown in Fig. 7:

\subsection{MPPT control for sunshine photovoltaic pumping systems}

2.4.1 MPPT adaptive network based fuzzy inference system (ANFIS)

The neuro-fuzzy inference is a combination of Artificial Neural Network (ANN) and Fuzzy Logic controller (FLC). The ANN identifies the patterns and conforms to them to deal with altering environments. On the order hand, the fuzzy inference systems (FIS) combine the human knowledge and carry out the inference and process

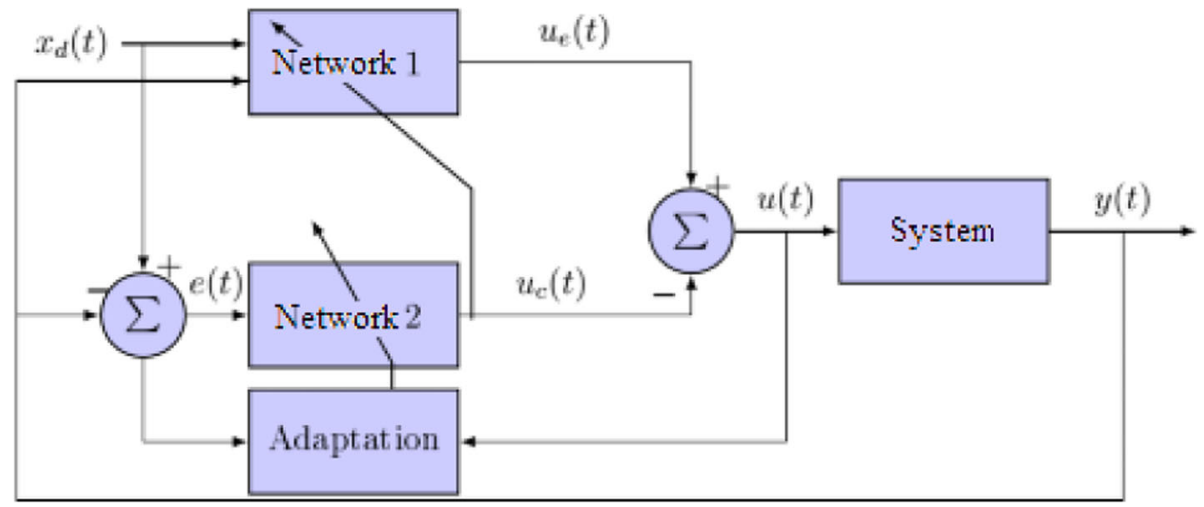

Fig. 13 Sliding-neural network modelling architecture 


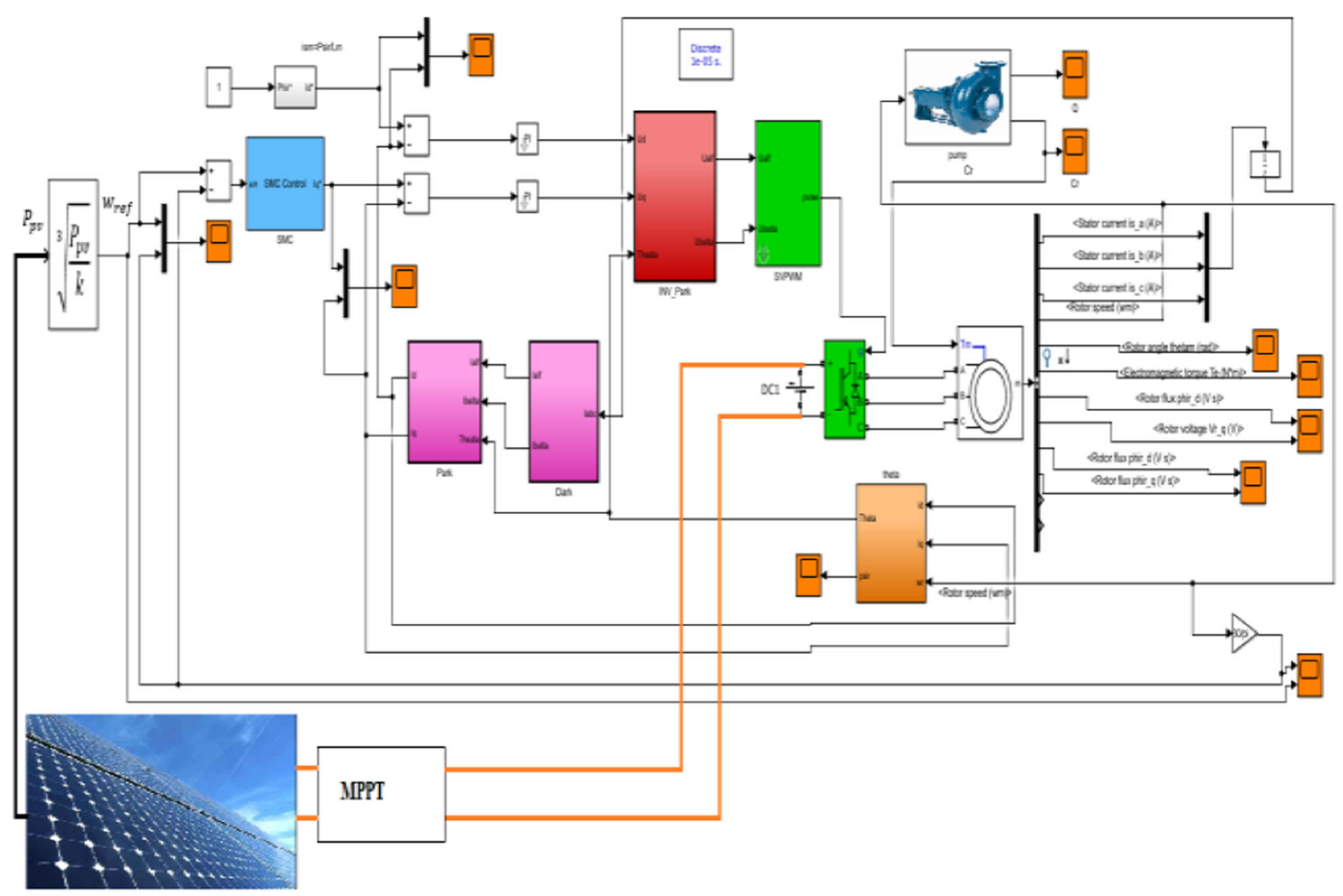

Fig. $14 M A T L A B /$ Simulink model of the pumping system

of decision making [22]. Two common fuzzy models, the Mamdani and Takagi-Sugeno-Kang (TSK), are defined for FIS.

The ANFIS is only able to use the TSK fuzzy model due to its high calculative efficiency, adaptive techniques and built in optimum. The controller provides smooth less in convergence because of the fuzzy TSK inference and adaptability as a result of ANN back-propagation

Table 3 Motor pump set parameters

\begin{tabular}{lll}
\hline Parameter & Value & Unit \\
\hline Induction motor Parameters & & \\
Rated voltage (RMS) & 400 & $\mathrm{~V}$ \\
Frequency & 50 & $\mathrm{~Hz}$ \\
Rated speed & 1430 & $\mathrm{rpm}$ \\
Stator winding resistance, $R_{s}$ & 6.3 & $\Omega$ \\
Rotor winding resistance, $R_{r}$ & 6.3 & $\Omega$ \\
Leakage reactance, $\left.x\right|_{s}=x_{r}$ & 0.1568 & $\Omega$ \\
Magnetizing reactance, $x_{m}$ & 0.15 & $\Omega$ \\
Poles, p & 4 & \\
Centrifugal pump Parameters & & $\mathrm{m} / \mathrm{h}$ \\
$Q$ & 18 & $\mathrm{~m}$ \\
$\mathrm{H}$ & 10 & \\
\hline
\end{tabular}

algorithms [23]. The structure of a typical five-layer ANFIS system is illustrated in Fig. 8.

In the first layer, MFs will be defined for each of inputs. In the second layer, each node via multiplication calculates the firing strength of a rule. The firing strength is normalized in layer 3 . Two common rules in TSK fuzzy model are defined as:

Rule 1: if $x$ is $A_{1}$ and $y$ is $B_{1}$, then $f_{1}=a_{1} x+b_{1} y+c_{1}$;

Rule 2: if $\boldsymbol{x}$ is $A_{2}$ and $\boldsymbol{y}$ is $B_{2}$, then $\boldsymbol{f}_{2}=a_{2} x+b_{2} y+c_{2}$.

Where $\boldsymbol{a}_{\boldsymbol{i}}, \boldsymbol{b}_{\boldsymbol{i}}$ and $\boldsymbol{c}_{\boldsymbol{i}}$ are the design parameters defined in the training plant. Also, $\boldsymbol{A}_{\boldsymbol{i}}$ and $\boldsymbol{B}_{\boldsymbol{i}}$ are the fuzzy sets input [24].

In MATLAB, a structure of the model is determined by using the inputs, output, MFs, and the relationship among them. After that, the inputs and output training data set should be collected to train the ANFIS. In fact, the ANFIS can estimate the MF's parameters by either back propagation algorithms alone or the so-called hybrid mode which is a combination of least squares estimation (LSE) and back propagation.

MATLAB/Simulink model of PV module is used to generate the training data set for ANFIS by varying the operating temperature in steps of $5^{\circ} \mathrm{C}$ from $15^{\circ} \mathrm{C}$ to $65^{\circ} \mathrm{C}$ and the solar irradiance level in a step of $50 \mathrm{~W} / \mathrm{m}^{2}$ from $100 \mathrm{~W} / \mathrm{m}^{2}$ to $1000 \mathrm{~W} / \mathrm{m}^{2}$. 


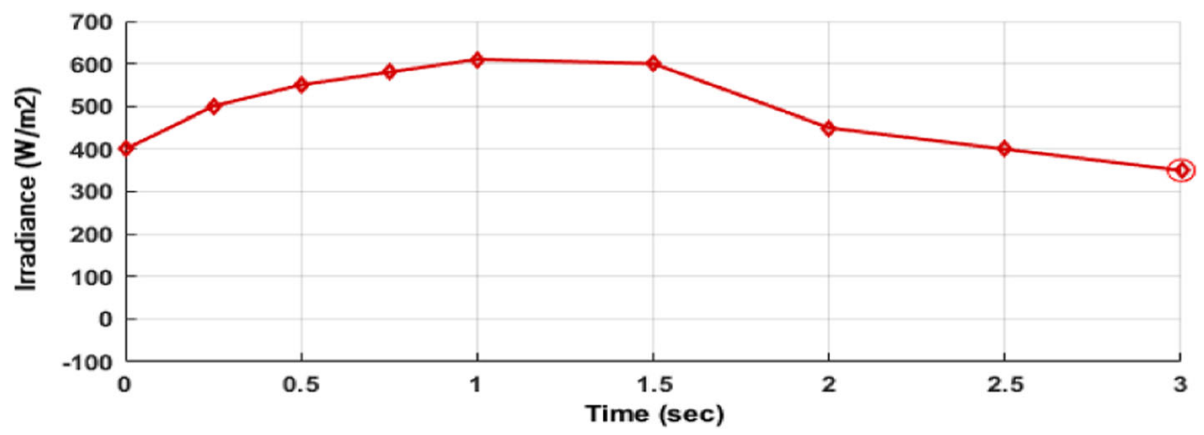

Fig. 15 Solar irradiance waveform

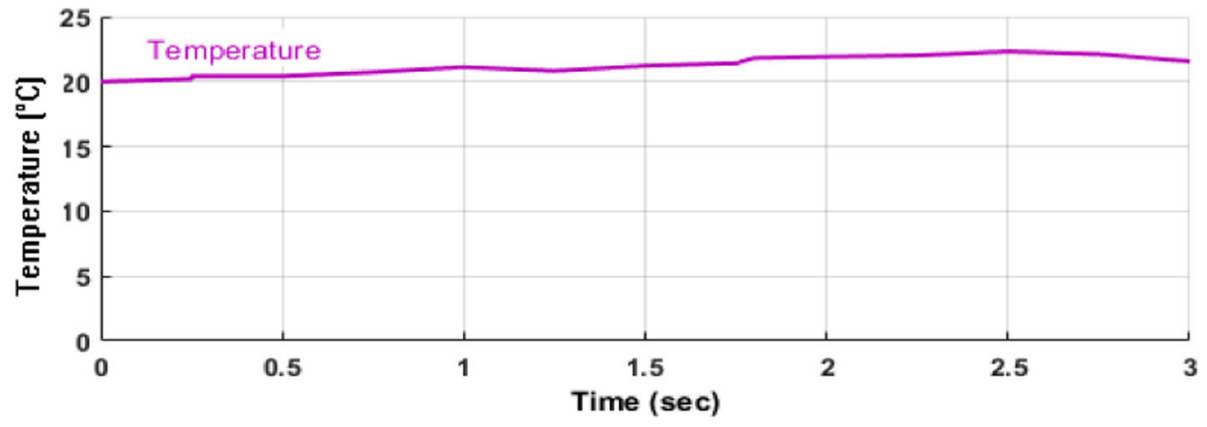

Fig. 16 Temperature waveform

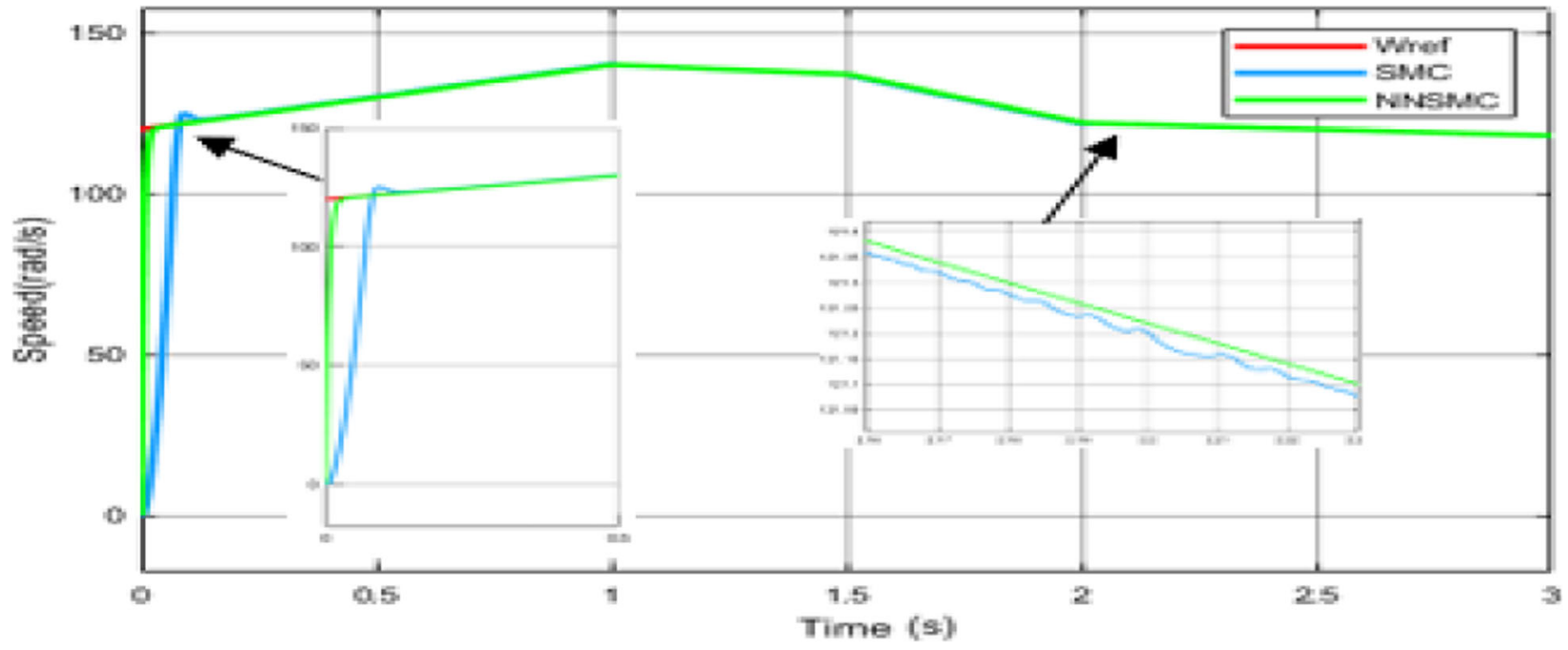

Fig. 17 Waveform of induction motor mechanical speed 

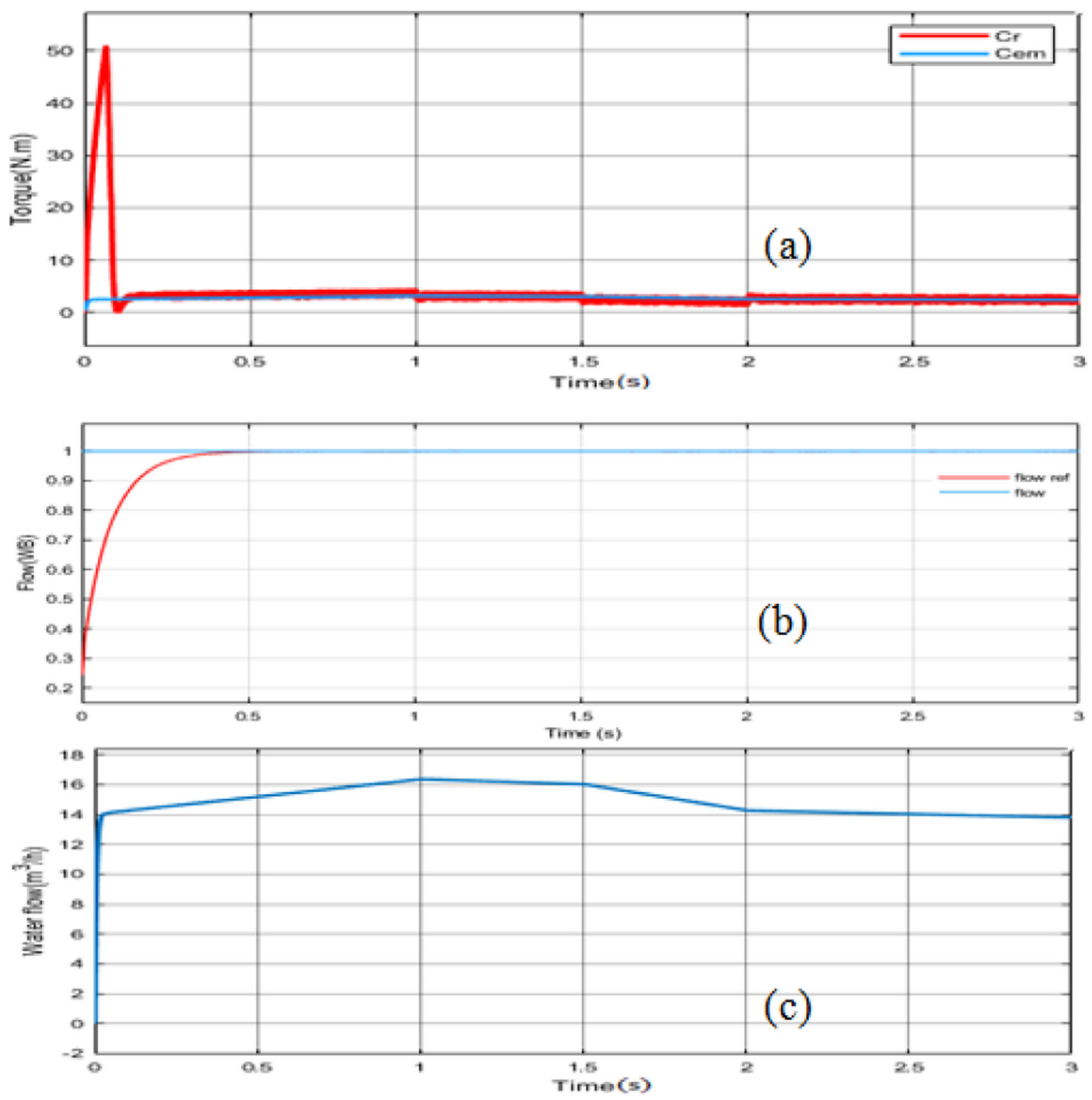

Fig. 18 Response of the system to the variation of $G$ and $T$

The Neural Network Controller (NNC) is used to estimate the PV array operating voltage $\left(V_{r e f}\right)$, which corresponds to Pmax at any given solar radiation and cell temperature. Therefore, the inputs to the controller are the solar radiation and the cell temperature. The output of the controller is the optimum operating voltage.

The network is trained for 20,000 epochs and the target error is set to $2.34 \%$. The training error waveform is depicted in Fig. 9, and the structure of ANFIS for this controller is shown in Fig. 10. The advantages of the method are its rapid tracking speed and high tracking accuracy.
Fig. 11 represents membership functions for the two inputs, namely, solar irradiance and PV cell temperature. Figure. 12 shows a fuzzy rule for the ANFIS inputs and output are applied after training.

\subsubsection{Sliding mode control design}

The basic principle of sliding mode control consists in moving the state trajectory of the system toward a predetermined surface called sliding or switching surface, and in maintaining it around this latter with an appropriate switching logic [25]. This is similar to a feed-forward controller that provides the control that should be applied to 


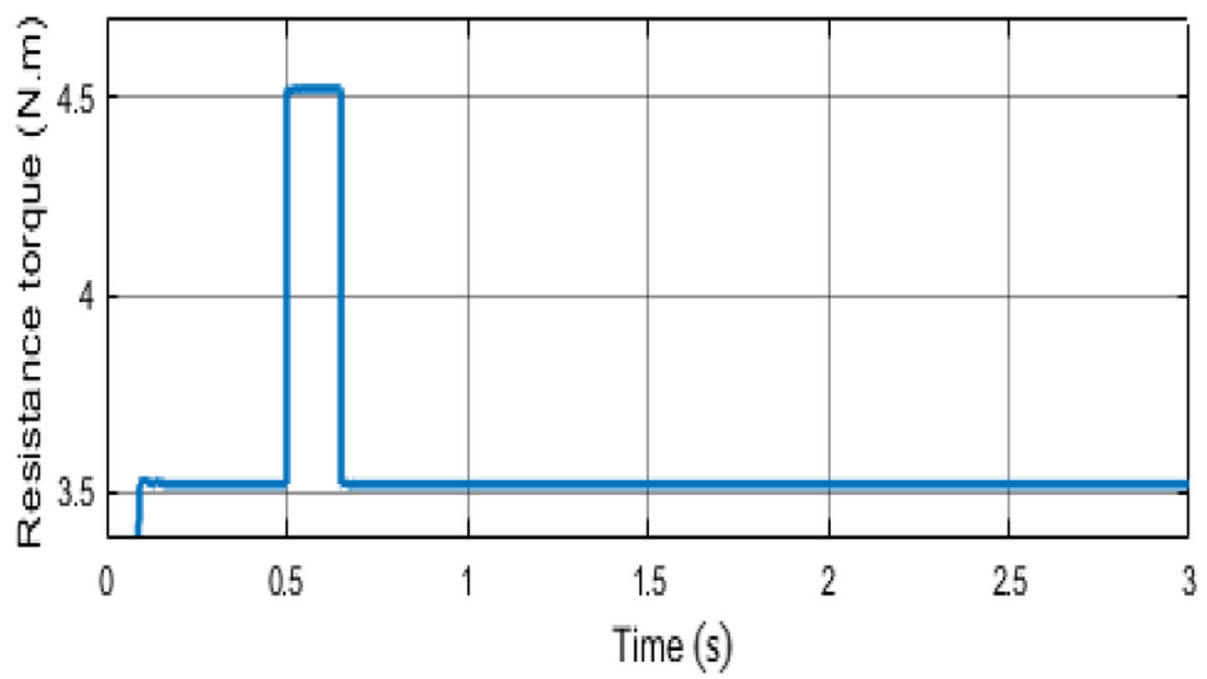

Fig. 19 Load torque profile

track a desired trajectory, which is in this case, the userdefined sliding surface itself. Therefore, the design of a sliding mode controller has two steps, namely, the definition of the adequate switching surface $S$ (.) and the development of the control law or the switching logic $u$.

The main disadvantage of Sliding Mode Control (SMC) is the high switching frequency $[26,27]$. To remedy this phenomenon, the control must adapt to changes in parameters or external disturbances. Therefore, a Sliding-Neural Network is proposed to overcome the chattering phenomenon.

\subsubsection{Sliding mode surface}

Consider a nonlinear system, which can be represented by the following state space model in a canonical form [16]:

$$
\{x \cdot=f(x, t)+g(x, t) u+d(t) y(t)=x(t)
$$

where, $x \in \Re^{n}$ is the state vector, $u \in \Re^{n}$ is the control vector, $y \in \Re^{n}$ is the output vector, $f(x, t)$ and $g(x, t)$ are two nonlinear continuous uncertain functions supposed bounded.

The objective of control law $u(t)$ to force the system output $y(t)$ in above equation and reference signal. We take the general eq. (19) to determine the sliding surface that given by:

$$
S(x)=\left(\frac{d}{d t}+\lambda\right)^{n-1} e(x)
$$

where $e(x)$ is the difference between the controlled variable and its reference $e(x)=x \cdot-x$.

With: $x=\left[x, x \cdot \ldots, x^{n-1}\right]^{T}$;

$\lambda$ : Positive constant;

$n$ : The number of times to derive the surface to obtain the control;

$x$ : The controlled variable.

\subsubsection{Application of neural networks in sliding mode control}

The integration of Neural Networks (NN) in a sliding controller whose architecture proposed by [28], is given in Fig. 13 where two neural networks are used in parallel to achieve the equivalent command. The input of the first network consists of the desired state and the current state while the input of the second network is the surface $S$.

\subsubsection{Sliding mode control of induction motor}

The two switching functions defining the sliding surfaces are given by:

$$
S(\Omega)=\Omega_{r e f}-\Omega
$$

then:

$$
S \cdot(\Omega)=\Omega \cdot r e f-\Omega
$$

By replacing in eq. (21), the expression of $\Omega$. taken from eq. (11), and introducing the equivalent command $\left(i_{s q}=i_{s q, e q}+i_{s q, n}\right)$ we will have:

$$
S \cdot(\Omega)=\Omega \cdot r_{r e f}-\left(\frac{3 p L_{m}}{2 J} \phi_{r d, r e f}\left[i_{s q, e q}+i_{s q, n}\right]-\frac{p}{J} C_{r}-\frac{f}{J} \Omega\right)
$$

During the sliding phase and at steady state $S(\Omega)$, so $S$ $\cdot(\Omega)=0$ and $i_{s q, n}=0$ from which we derive the expression of $i_{s q, e q}$ :

$$
i_{s q, e q}=\frac{2 J}{3 p L_{m} \phi_{r d, r e f}}\left(\Omega \cdot r e f+\frac{p}{J} C_{r}+\frac{f}{J} \Omega\right)
$$

The action of the discontinuous command $i_{s q, n}$ must satisfy the condition $S S \cdot<0$. By restoring eq. (22) in eq. (23), it will result: 


$$
S \cdot(\Omega)=-\frac{3 p L_{m}}{2 J} \phi_{r d, r e f} i_{s q, n}
$$

\section{Simulation results}

In order to demonstrate the effectiveness of the proposed control technique applied to the photovoltaic water-pumping system, some simulations have been carried out. The proposed design scheme which is described by Fig. 14 was implemented in MATLAB/Simulink software using parameters given in Table 3.
3.1 Effects of the variation of the value of the solar irradiation $G$ and the temperature $T$ on the storage of the water

In a first step, we choose to vary the solar irradiance value and the temperature $\mathrm{T}$ as it is shown in Figs. 15 and 16, and to see its impact on the performances of the photovoltaic water pumping.

Figure. 17 illustrates the waveform of the mechanical speed of the induction motor which is closed to its optimal value.

The same remark is given to the electromagnetic torque shown in Fig. 18a and the flow shown in Fig. 18b. It is clearly shown that the induction motor is
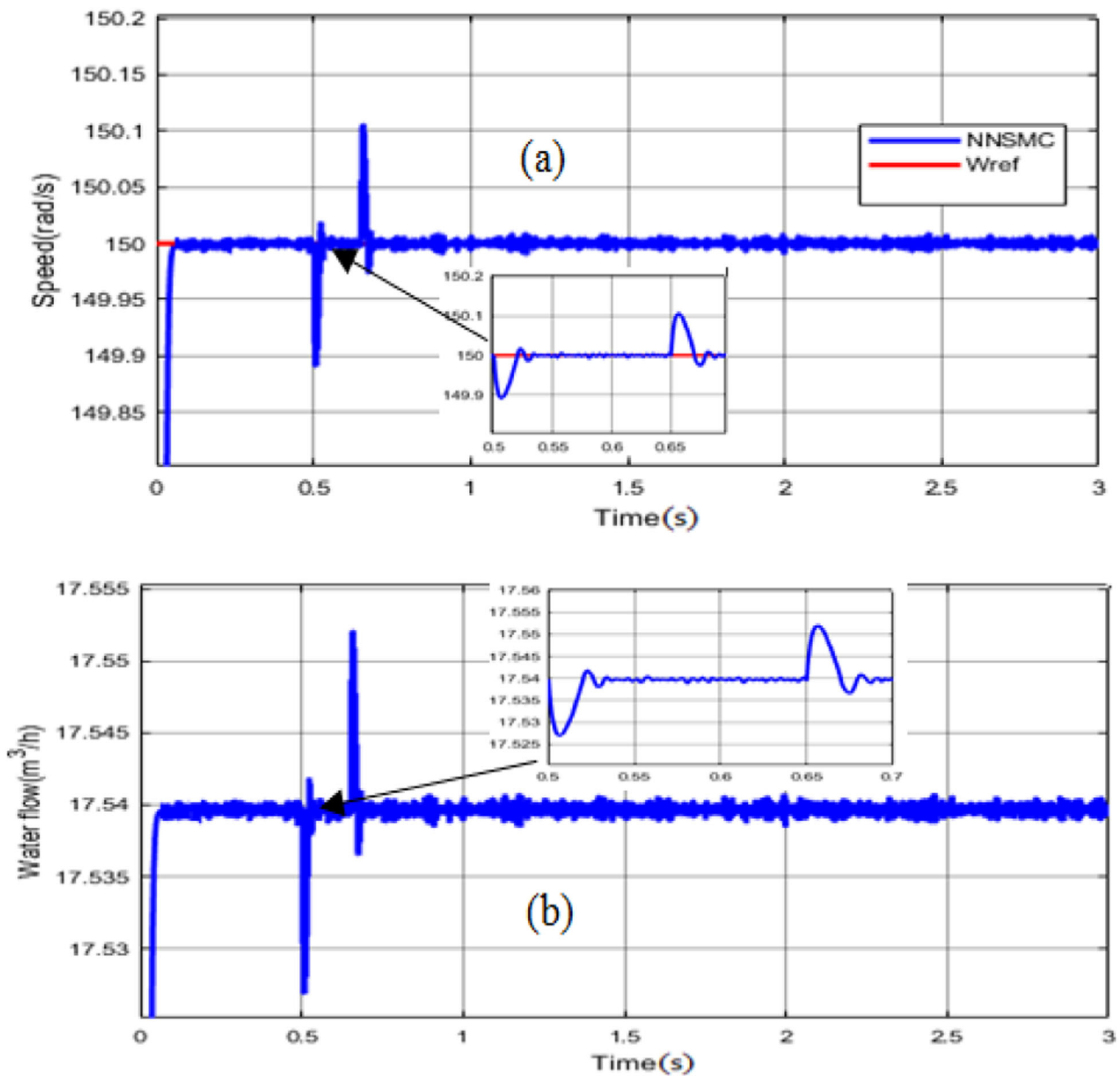

Fig. 20 Speed response under load torque variation 

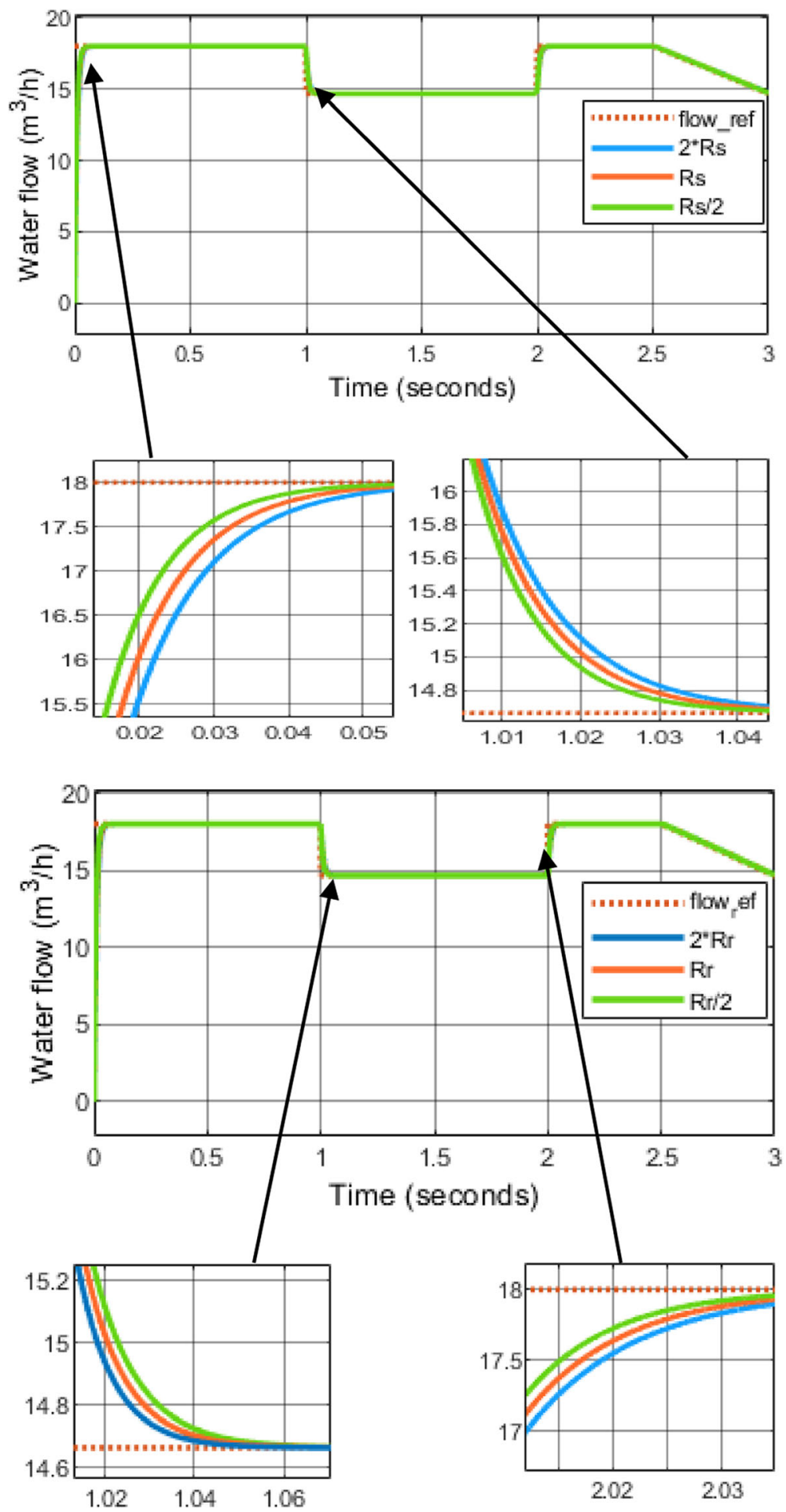

Fig. 21 Robustness test for a variation in the rotor and stator resistances

operating at its optimal conditions. Figure. 18c, represents the waveform of the centrifugal pump flow which is closed to its optimal value for each value of $G$ and $T$.

\subsection{Robustness study}

3.2.1 Variation in the load torque

In a second step, we choose to vary load torque (resistance torque) $C_{r}$ to $30 \%$ of its initial value as shown in 

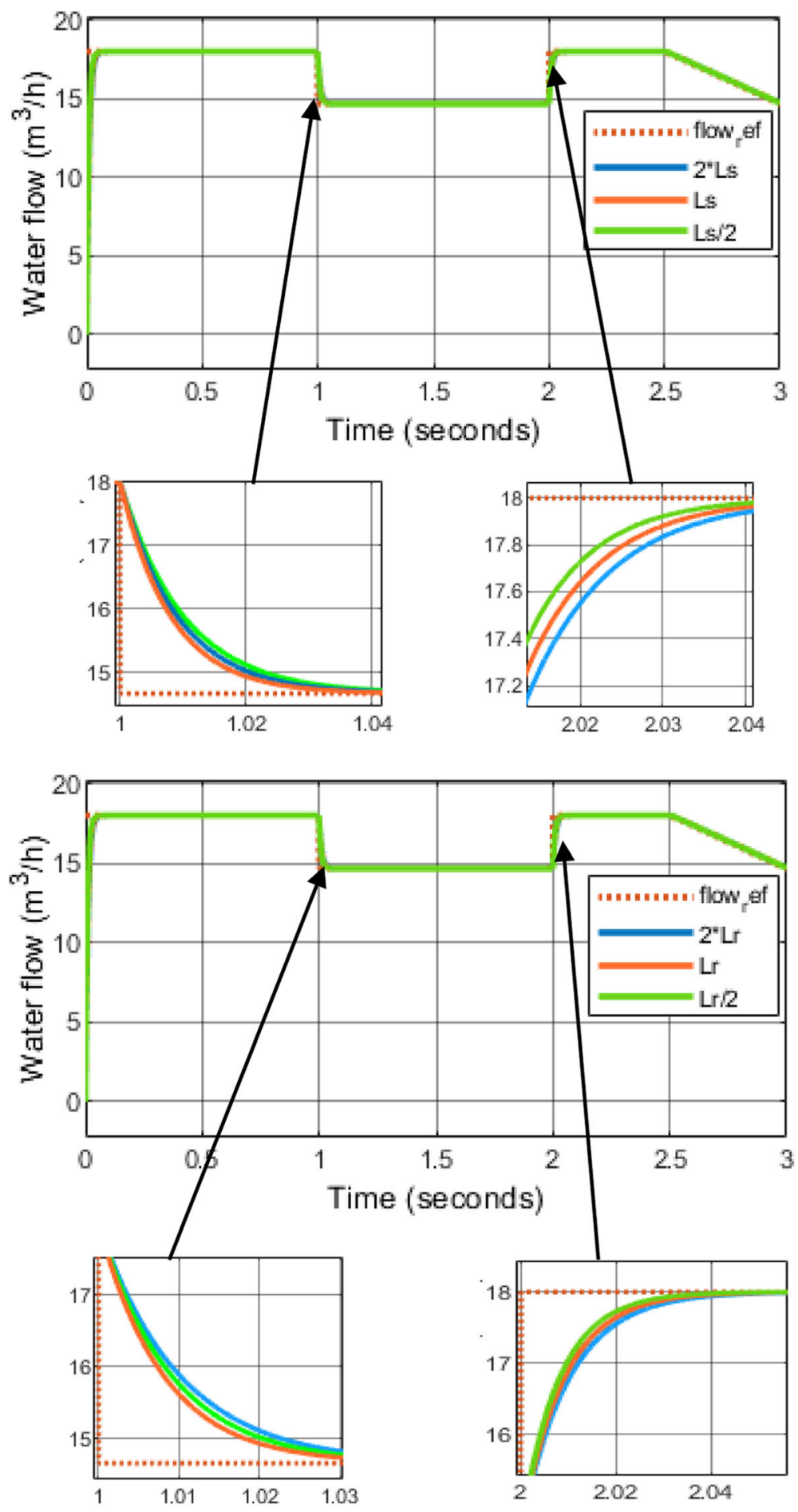

Fig. 22 Robustness test for a variation in the rotor and stator inductances

Fig. 19, in order to prove the robustness of the system against external disturbances.

Figure 20a and b, shows respectively the waveform of the motor speed and the pump flow. The rotor speed is lightly affected by the variation of the load torque at a short transient, and then return to the optimal value. The same remark is given to the centrifugal pump flow which proves that the water pumping system operating at its optimal conditions. Then, the robustness of the controlled system is achieved by the neural network-sliding mode controller. 


\subsubsection{Variation in the parametric of induction motor}

The performance of the proposed control scheme which is based on NN-Sliding Mode Control are assessed again with other four tests which are performed to study the influence of the parametric variations for the stator and rotor resistances, and stator and rotor inductances of the induction motor.

\subsubsection{Variation in the stator and rotor inductances}

The simulation results of robustness tests illustrated by Figs. 21 and 22 for NN-Sliding Mode Control, show clearly that the parameter variations of the induction motor have practically no effect on the dynamics of speed response, ie on the flow of water (or the need for water) even in the presence of parametric variations. A variation in the resistance or inductance of its nominal value does not affect the response, but the rise varies by a few milliseconds.

\section{Discussion and conclusion}

The photovoltaic conversion systems are characterized by the variation of their electrical power according to the weather conditions because the power transferred to the load rarely corresponds to the maximum power that can provide the Photovoltaic generator (GPV). Therefore, a command requiring the GPV to produce the maximum available power at its terminals is essential to improve the efficiency of the conversion system. For this, we have proved that the use of the developed ANFISMPPT algorithm can solve the degradation problem of the GPV performance, following the power variation, according to climatic factors which have enabled a good tracking of the Maximum power point.

Thus, to improve the performance of a photovoltaic pumping system, an evaluation of the control without speed sensor based on sliding mode of the neural network with the fuzzy logic has managed to regulate the speed of the engine, then to optimize system performance. In addition, the strength quality of the proposed controller appears clearly in the tests results under load torque variation. Finally, this installation helps to minimize the total cost since we choose to store the water and not the energy that requires the use of electric batteries.

\section{Abbreviations \\ G: Generator; PV: Photovoltaic; AC : Alternating Current; ANFIS: Adaptive Neuro-Fuzzy Inference System; ANN: Artificial Neural Network; DC : Direct Current; FIS: Fuzzy Inference Systems; FLC: Fuzzy Logic Controller; IM: Induction Motor; LSE: Least Squares Estimation; MPPT: Maximum Power Point Tracking; NN: Neural Network; P\&O: Perturb and Observe; \\ PV: Photovoltaic; SMC: Sliding Mode Control}

\section{Acknowledgements}

None.

\section{Authors' contributions}

$\mathrm{HH}$ conceived and designed the research study. $\mathrm{HH}$ and $\mathrm{CBR}$ formulated the algorithm, performed the verification studies and the simulations. AZ provides guidance on algorithm development and writing $\mathrm{HH}, \mathrm{CBR}$ and $\mathrm{AZ}$ wrote, reviewed, and edited the manuscript. All authors read and approve the final version of the manuscript.

Funding

None.

Availability of data and materials

None.

\section{Competing interests}

The authors declare that they have no competing interests.

Received: 7 June 2019 Accepted: 15 November 2019

Published online: 16 December 2019

References

1. Richard, N. (2009). Traversing the mountaintop: World fossil fuel production to 2050. Philos Trans R Soc Lond Ser B Biol Sci, 3067-3079.

2. Roberto, F., \& Sonia, L. (2008). Energy comparison of MPPT techniques for PV systems. WSEAS Transcations Power Syst, 3, 446-455.

3. Fangrui, L., Yong, K., Yu, Z., \& Shanxu, D. (2008). Comparison of $P \& O$ and hill climbing MPPT methods for grid-connected PV converter (pp. 804-807). ICIEA: Industrial Electronics and Applications.

4. Galotto, M. A. G., Sampaio, L. P., Azevedo, M., Canesin, G., \& Canesin, C. A. (2013). Evaluation of the main MPPT techniques for photovoltaic applications. IEEE Trans Ind Electron, 1156-1167.

5. AdelMellit Soteris, A. (2008). Artificial intelligence techniques for photovoltaic applications: A review. Elsevier -Prog Energy Combustion Sci, 574-632.

6. Li, X., Li, Y., \& Seem, J. E. (2013). Maximum power point tracking for photovoltaic system using adaptive extremum seeking control. IEEE Trans Control Syst Technol, 2315-2322.

7. Ramaprabha, R., Gothandaraman, V., Kanimozhi, K., Divya, R., \& Mathur, B. L. (2011). Maximum power point tracking using GA-optimized artificial neural network for solar PV system. Electrical Energy Systems (ICEES), 264-268.

8. Hamdi, H., Ben Regaya, C., \& Zaafouri, A. (2019). Real-time study of a photovoltaic system with boost converter using the PSO-RBF neural network algorithms in a MyRio controller. Solar Energy, 183, 1-16.

9. Chokri, B. S., \& Mohamed, O. (2011). Comparison of fuzzy logic and neural network in maximum power point tracker for PV systems. Electr Power Syst Res, 43-50.

10. Bendib, B., Krim, F., Belmili, H., Almi, M.F., Bolouma, S. (2014). An intelligent MPPT approach based on neural-network voltage estimator and fuzzy controller, applied to a stand-alone PV system. IEEE 23rd Int. Symp on Industrial Electronics (ISIE), 404-409.

11. Rajan, K. B. S. (2014). Buck-boost converter fed BLDC motor drive for solar PV array-based water pumpin. IEEE international conference on power electronics drives and energy systems (PEDES), 1-6.

12. Farhani, F., Ben Regaya, C., Zaafouri, A., \& Chaari, A. (2013). Adaptive full order observer for Sensorless induction motor control. Trans Mach Des, 10-18.

13. Zaafouri, A., Ben Regaya, C., \& Chaari, A. (2013). Backstepping approach applied for control and on-line adaptation of the rotor resistance. World App/ Sci J, 1120-1126.

14. Srinu, B. N. (2014). Comparison of Direct and Indirect Vector Control of Induction Motor. Int J New Technol Sci Eng, 110-131.

15. Domenico, C., Francesco, P., Giovanni, S., \& Angelo, T. (2002). FOC and DTC: Two viable schemes for induction motors torque control. IEEE Trans Power Electron, 779-787.

16. Ben Regaya, C., Zaafouri, A. Z., \& Chaari, A. (2014). A New Sliding Mode Speed Observer Of Electric Motor Drive Based on Fuzzy-Logic. Acta Polytechnica Hungarica, 219-232.

17. Mohd, Z., Mohd, R., Soh, A. C., Abdul Rahim, N. (2012). Adaptive P\&O- fuzzy control MPPT for PV boost dc-dc converter. IEEE international conference on power and energy, 524-529.

18. Ben Regaya, C., Farhani, F., Zaafouri, A., \& Chaari, A. (2018). A novel adaptive control method for induction motor based on Backstepping approach using dSpace DS 1104 control board. Mech Syst Signal Process, 466-481.

19. Farhani, F., Ben Regaya, C., Zaafouri, A., \& Chaari, A. (2017). Real time PIbackstepping induction machine drive with efficiency optimization. ISA Trans, 348-356.

20. Arrouf, M., \& Ghabrour, S. (2007). Modelling and simulation of a pumping system fed by photovoltaic generator within the Matlab/Simulink programming environment. Desalination, 23-30. 
21. Serir, C., \& Rekioua, D. (2015). Control of photovoltaic water pumping system. J Electr Eng, 339-344.

22. Esram, T., \& Chapman, P. L. (2007). Comparison of photovoltaic array maximum power point tracking techniques. IEEE TRANS ENERGY CONVERSION EC, 439-449.

23. Otieno, C. A., Nyakoe, G. N., \& Wekesa, C. W. (2009). A neural fuzzy based maximum power point tracker for a photovoltaic system. IEEE AFRICON, 1-6.

24. Denaï, M. A., Palis, F., \& Zeghbib, A. (2007). Modeling and control of nonlinear systems using soft computing techniques. App/ Soft Comput, 728-738.

25. Mahmoudi, M. O., Madani, N., Benkhoris, M. F., \& Boudjema, F. (1999). Cascade sliding mode control of a field-oriented induction machine drive. Eur Phys J AP, 217-225.

26. Hardik, A.S., Ami, T.P. (2014). Controller design via sliding mode control approach of induction motor. IEEE international conference on Advanced Computing \& Communication Technologies, 541-546.

27. Saghafinia, A., Wooi, P. H., \& Khalaf, G. (2015). Adaptive fuzzy sliding-mode control into chattering-free IM drive. IEEE Trans Ind Appl, 692-701.

28. Ertugrul, M., \& Kaynak, O. (2000). Neuro sliding mode control of robotic manipulators. Mechatronics, 243-267.

\section{Submit your manuscript to a SpringerOpen ${ }^{\circ}$ journal and benefit from:}

- Convenient online submission

- Rigorous peer review

- Open access: articles freely available online

High visibility within the field

- Retaining the copyright to your article

Submit your next manuscript at $\boldsymbol{\nabla}$ springeropen.com 